\begin{tabular}{lc|}
\hline \hline \hline & International Journal of Current Research \\
$f$ & and Academic Review \\
EXCELLENT \\
PUBLISHERS
\end{tabular}

doi: https://doi.org/10.20546/ijcrar.2018.606.002

\title{
Exclusive Breastfeeding and the Impact on Neonatal Mortality of Low Birth Weight
}

\author{
Satrinawati Berkat* \\ Department of Midwifery, Health Polytechnic of Aceh, Aceh Province, Indonesia \\ *Corresponding author
}

\begin{abstract}
Low birth weight (LBW) was defined as the birth weight of less than 2500 gram and included the preterm birth. In 2016, 2.6 million under-five deaths in the world and occur during the neonatal period (46\%). Most of the neonatal death due to preterm birth (31.2\%). One of the interventions to reduce neonatal mortality are breastfeeding. This study aim to asses the impact of exclusive breastfeeding on neonatal mortality of LBW in Aceh province, Indonesia. The study was observational with unmatched case control and conducted in 8 districts in Aceh Province. Population in this study was the LBW who delivered between 2011 to 2014 . Total sample was 500 (1:1), 250 cases and 250 control. The results show230 (92.0\%) neonates in the case group did not receive exclusive breast feeding and and 117 (46.8\%) in the control group. Simple logistic regression analysis found there was a significant association between exclusive breast feeding and neonatal mortality of LBW ( $\mathrm{p}<0.01$ ) with OR of 13.0 (95\% CI: 7.77- 21.9). The conclusion was exclusive breastfeeding has impact on neonatal mortality of the LBW. Exclusive breastfeeding is the best food for LBW and as the one ways to reduce mortality in the neonatal period.
\end{abstract}

\section{Introduction}

The first 28 days of life (neonatal period) is the represent the most vulnerable time for a child's survival. In 2016, 2.6 million deaths, or roughly $46 \%$ of all under-five deaths, occur during this period. This translates to 7000 newborn deaths every day. The majority of the neonatal deaths are concentrated in the first day and week, with about 1 million dying on the first day and close to one million dying within the next six days (WHO, 2016). Most of the neonatal death due to preterm birth or 31.2\% of all neonatal mortality (UNICEF, 2018). Preterm is defined as babies born alive before 37 weeks of pregnancy are completed (WHO, 2018), and premature birth is part of the low birth weight (LBW).
Low birth weight was defined as birth weight of less than 2500 grams (WHO \& UNICEF, 2004). Categorize of the LBW are: preterm birth, intrauterine growth restriction (IUGR) and Preterm birth and IUGR (Lawn, et al., 2005). LBW does not only contribute to neonatal morbidity, but may lead to neonatal mortality. Even though LBW is not the immediate cause of mortality, it is a major contributor and may jeopardize a newborns chances of survival. In addition, LBW does not only affect newborns growth but also may affect their entire life. It is the main cause of poor childhood growth and high risk diseases in the adult, such as diabetes, hypertension and cardiovascular. For baby girls, they are more likely to have LBW babies when they become mothers (WHO \& UNICEF, 2004). 
The prevalence rate of LBW worldwide between 20082012 was $15 \%$ of all live births. The region with the highest rate of LBW in the world was South Asia (28\% of all live births), and the lowest rate was East Asia and Pacific or $6 \%$ of all live births (UNICEF, 2014). In Indonesia the percentage of LBW between 2011- 2013 was $10.2 \%$ of live births (Kemenkes RI, 2013). The large number of LBW contribute to the higher neonatal mortality rate in the world.

Reducing neonatal mortality is increasingly important not only because the proportions of under-five deaths that occur during the neonatal period is increasing as under-five mortality declines but also because the health interventions needed to address the major causes of neonatal deaths generally differ from those needed to address other under-five deaths. On current trends, more than 60 countries will miss the SDG target of reducing neonatal mortality to at least as low as 12 deaths per 1000 live births by 2030. About half of them will not reach the target by 2050 . These countries carry about 80 per cent of the burden of neonatal deaths in 2016. (WHO, 2016).

One of the interventions to reduce neonatal mortality and a part of the global strategy for children health 20162030 are breastfeeding (United Nation, 2015). Breastfeeding is an unequalled way of providing ideal food for the healthy growth and development of infants; it is also an integral part of the reproductive process with important implications for the health of mothers. Breastfeeding is when a mother breastfeeds her baby, she feeds it with milk directly from her breasts rather than with artificial or cow's milk from a bottle. Breast milk is the natural first food for babies, it provides all the energy and nutrients that the infant needs for the first months of life, and it continues to provide up to half or more of a child's nutritional needs during the second half of the first year, and up to one-third during the second year of life. Breast milk promotes sensory and cognitive development, and protects the infant against infectious and chronic diseases (WHO, 2018).

Breast milk contains all the nutrients that an infant needs in the first 6 months of life, including fat, carbohydrates, proteins, vitamins, minerals and water. It is easily digested and efficiently used. Breast milk also contains bioactive factors that augment the infant's immature immune system, providing protection against infection, and other factors that help digestion and absorption of nutrients. Breast milk contains about $3.5 \mathrm{~g}$ of fat per 100 $\mathrm{ml}$ of milk, which provides about one half of the energy content of the milk. The fat is secreted in small droplets, and the amount increases as the feed progresses (WHO, 2009). There are sufficient vitamins for an infant in the breast milk, unless the mother herself is deficient (Cernadas et al, 2006).

Breast milk protein differs in both quantity and quality from animal milks, and it contains a balance of amino acids which makes it much more suitable for a baby. The concentration of protein in breast milk $(0.9 \mathrm{~g}$ per $100 \mathrm{ml})$ is lower than in animal milks. The much higher protein in animal milk can overload the infant's immature kidneys with waste nitrogen products. Breast milk also contains about $7 \mathrm{~g}$ lactose per $100 \mathrm{ml}$, which is more than in most other milk, and is another important source of energy. The concentration of protein in breast milk $(0.9 \mathrm{~g}$ per $100 \mathrm{ml})$ is lower than in animal milks. The much higher protein in animal milk can overload the infant's immature kidneys with waste nitrogen products (Riordan J, 2004). Consumption cow's milk may increase the risk of wheezing in children under age five (Safri M. 2018).

To fulfilling optimal nutrition, WHO recommended exclusive breastfeeding to the infant.Exclusive breastfeeding is the infant only receives breast milk without any additional food or drink, not even water, and recommended to give exclusive breastfeeding to the infant until 6month(WHO. 2018). In globally, only $40 \%$ of infants under six months of age are exclusively breastfed (WHO, 2017). In 2016, percentage infant who receive exclusive breastfeeding in Indonesia was $29.5 \%$ and in Aceh province was 23.5\% (Kemenkes RI, 2017).

Many benefit of exclusive breastfeeding. Some previous studies showed that exclusive breastfeeding during neonatal period will increase chances for survival of infants. A study conducted inrural Ghana showed that the risk of neonatal death was fourfold higher in neonates who gave milk-based fluids or solids as compared to neonates who received exclusive breastfeeding in the neonatal period (Edmond et al., 2006). In another study, Edmond et al., (2007) concluded that established neonatal breastfeeding days 2-28 would increase chances of survival in the neonatal period. The risk of neonatal death in neonates who received partial breastfeeding was 5.7 times higher than neonates who were breastfed exclusively. Exclusive breastfeeding helps to prevent hypothermia and hypoglycemia in newborn babies, both of which were contributory causes of early neonatal deaths especially among low birth weight and premature babies (Huffman et al., 2001). Children who did not 
accept exclusive breastfeeding had a higher risk of allergic rhinitis than children who accept exclusive breastfeeding (Safri et al., 2018).

This study aim to asses the impact of exclusive breastfeeding on neonatal mortality of LBW in Aceh province, Indonesia

\section{Materials and Methods}

\section{Design}

This study was observational with unmatched case control.

\section{Study site}

The study conducted in 8 districts of 23 districts in Aceh Province, Indonesia.

\section{Population and sample}

Population of this study was low birth weight neonates in Aceh Province and delivered between 2011to 2014, which include those who survived or died during the neonatal period. Sample were divided into two groups:LBW neonates who died in the neonatal period (case group) and LBW neonates who survived in the neonatal period (control group). The total sample was 500 neonates $(1: 1), 250$ cases and 250 control.

\section{Data collection}

It is started in early February 2012 and completed in August 2014, in 8 districts/ municipalities in Aceh province, Indonesia.

\section{Inclusion and exclusion criteria}

The criteria will be shown in table 1

\section{Instrument}

Data collected base on a questionnaire that filled by parent and assisted by the enumerator when the study conducted.

\section{Variables}

The dependent variablein this study was neonatal mortality that divided into two factors; neonate who died during the neonatal period (case group) and neonate who alive during the neonatal period (control group). Independent variables was exclusive breastfeeding during the neonatal period, receive or did not receive. Definition of the exclusive breastfeeding in the variable was the infant only receives breast milk without any additional food or drink, not even water during neonatal period.

\section{Data analysis}

Descriptive statistic was used for univariate analysis and single logistic regression was used for bivariate analysis.

\section{Results and Discussions}

\section{Result}

\section{A. Descriptive analysis}

Descriptive analysis of the characteristic of the neonate, mother and home care (exclusive breastfeeding) will be shown in Table 2 Inthe characteristic of neonate divide into sex, birth weight and gestational age. Characteristic of sex shown that among those in the case group, 101 $(40.4 \%)$ neonates were girls, and $149(59.6 \%)$ neonates were boys. In the control group, 140 neonates (56\%) were girls and 110 neonates were boys $(44 \%)$. In the birth weight showed that $171(68.4 \%)$ neonates in the case group were born with weight $\geq 1500$ grams and 79 $(31.6 \%)$ neonates were born with weight $<1500$ grams. In another group, 243 neonates $(97.2 \%)$ were born with weight between 1500- 2499 grams and $7(2.8 \%)$ for weight $<1500 \mathrm{~g}$. The mean birth weight in the case group was 1728 grams and the standard deviation (SD) was 416.8. Meanwhile, the mean birth weight in control group was 2063 grams with SD of 283.5. In the gestational age variable indicated that 44 neonates (17.6 $\%)$ in the case group were born full term and 206 neonates $(82.4 \%)$ were born preterm. Furthermore, 103 $(41.2 \%)$ neonates in the control group were born full term and 147 neonates $(58.8 \%)$ were born preterm. The mean gestational age in the case group was 32 weeks with SD of 4, and the mean in the control group was 35.1 weeks with SD of 3.3.

Characteristics of mothers consist of age, birth interval, parity and education level. In the characteristic of age the mother shown that most of the mothers recruited were aged between 20-35 years old (low risk). In the case group, $182(72.8 \%)$ of mothers were in 20-35 years old age group and $211(84.4 \%)$ were in the control group. The number of mothers who delivered at the age of $<20$ 
and $>35$ years old were $68(27.2 \%)$ in the case group and $39(15.6 \%)$ in the control group. The mean age of mothers in the case group was 28.7 years with SD of 6.6. Meanwhile, the age of mothers in the control group was 27.6 years with SD of 5.7 years. The birth interval was described as low risk (2-5 years from previous pregnancy) and high risk $(<2$ and $>5$ years from previous delivery) categories. There were165 (66\%) mothers delivered in the low risk category from case group and 201 (80.4\%) mothers from the control group. There were $85(34 \%)$ mothers in the case group and 49 $(19.6 \%)$ in the control group from high risk category of birth interval. The mean birth interval in the case group was $2.1 \pm 2.3$, and in the control group was $2.3 \pm 2.3$.

The parity shows that $134(53.6 \%)$ mothers in the case group and $147(58.8 \%)$ mothers in the control group delivered in the low risk category (the 2nd to 4th pregnancy). Mothers who delivered in the high-risk category (1st or $\geq 5$ th pregnancy) were $116(46.4 \%)$ in the case group and $103(41.2 \%)$ mothers in the control group. The mean value of parity in case group was 2.9 times with SD of 1.7, while in the control group was 2.4 \pm 1.4. In the maternal education level, 86 (34.4\%) mothers in case group graduated from senior high school,
$80(32 \%)$ mothers graduated from junior high school, 55 (22\%) mothers graduated from elementary school, and 7 (2.8\%) mothers graduated with a degree. In the control group, $99(39.6 \%)$ mothers graduated from senior high school, $68(27.2 \%)$ mothers graduated from junior high school, $47(18.8 \%)$ mothers graduated from elementary school and 26 (10.4\%) mothers obtained a diploma and 10 mothers had a bachelor degree.

In the characteristic of exclusive breastfeeding shown that $230(92.0 \%)$ neonates in the case group did not receive exclusive breast feeding and $117(46.8 \%)$ in the control group. Meanwhile, 20 neonates $(8.0 \%)$ in the case group receive exclusive breastfeeding and 113 $(53.2 \%)$ in the control group.

\section{a. Bivariate analysis}

The result of simple logistic regression analysis found there was a significant association between exclusive breast feeding and neonatal mortality of LBW $(\mathrm{p}<0.01)$ with OR of 13.0 (95\% CI: 7.77- 21.9). The neonates who did not receive exclusive breast feeding during their neonatal period had 13 times greater risk of death than neonates who obtained exclusive breastfeeding

Table.1 Inclusion and exclusion criteria

\begin{tabular}{|c|c|c|}
\hline Criteria & Cases & Control \\
\hline \multirow[t]{3}{*}{ Inclusion } & $\begin{array}{l}\text { 1. Born alive with birth weight between } \\
1,001-2,499 \text { grams }\end{array}$ & $\begin{array}{l}\text { 1. Born alive with birth weight between } \\
1,001-2,499 \text { grams }\end{array}$ \\
\hline & $\begin{array}{l}\text { 2. Born between } 2010 \text { to } 2013 \text { on the } \\
\text { study site }\end{array}$ & $\begin{array}{l}\text { 2. Born between } 2010 \text { to }-2013 \text { on the study } \\
\text { site }\end{array}$ \\
\hline & 3. Died before 29 days of life & 3. Survive until 28 days of life \\
\hline \multirow[t]{5}{*}{ Exclusion } & $\begin{array}{l}\text { 1. Moved from the study site before or } \\
\text { during data collection }\end{array}$ & $\begin{array}{l}\text { 1. Moved from study site before or during } \\
\text { data collection }\end{array}$ \\
\hline & 2. Presence of congenital abnormalities & 2. Presence of congenital abnormalities \\
\hline & 3. Multiple births & 3. Multiple births \\
\hline & 4. Hospitalized during neonatal periods & 4. Hospitalized during neonatal periods \\
\hline & $\begin{array}{l}\text { 5. The neonate was adopted in the } \\
\text { neonatal period }\end{array}$ & $\begin{array}{l}\text { 5. The neonate was adopted in the neonatal } \\
\text { period }\end{array}$ \\
\hline
\end{tabular}


Table.2 Characteristic of Neonates, mother's and exclusive breastfeeding

\begin{tabular}{|c|c|c|c|c|c|}
\hline \multirow[t]{2}{*}{ Characteristics } & \multicolumn{2}{|c|}{ Case (250) } & \multicolumn{3}{|c|}{ Control (250) } \\
\hline & $\mathbf{n}$ & $\%$ & $\mathbf{n}$ & & $\%$ \\
\hline \multicolumn{6}{|l|}{ b. Neonate } \\
\hline \multicolumn{6}{|l|}{ Sex of neonate } \\
\hline - Girl & 101 & 40.4 & 140 & & 56.0 \\
\hline - Boy & 149 & 59.6 & 110 & & 44.0 \\
\hline \multicolumn{6}{|l|}{ Birth weight } \\
\hline - $\quad$ MLBW (1500-2499 grams) & 171 & 68.4 & 243 & & 97.2 \\
\hline - $\quad$ VLBW (1001- 1499 grams) & 79 & 31.6 & 7 & & 2.8 \\
\hline Mean \pm sd & $1728 \pm$ & 416.8 & $2,063 \pm$ & 283.5 & \\
\hline \multicolumn{6}{|l|}{ Gestational Age } \\
\hline - Full term ( $\geq 37$ weeks) & 44 & 17.6 & 103 & & 41.2 \\
\hline - $\quad$ Pre term $(<37$ weeks $)$ & 206 & 82.4 & 147 & & 58.8 \\
\hline Mean \pm sd & $32 \pm 4.0$ & & $35.1 \pm 3.3$ & & \\
\hline \multicolumn{6}{|l|}{ b.Mother } \\
\hline \multicolumn{6}{|l|}{ Age } \\
\hline - Low risk (20-35 years old) & 182 & 72.8 & 211 & & 84.4 \\
\hline - High risk $(<20$ or $>35$ years old & 68 & 27.2 & 39 & & 15.6 \\
\hline Mean \pm sd & $28.7 \pm 6.6$ & & $28.7 \pm 6.6$ & & \\
\hline \multicolumn{6}{|l|}{ Birth interval } \\
\hline - Low risk (between 2-5 years) & 165 & 66.0 & 201 & & 80.4 \\
\hline - High risk (<2years or $>5$ years $)$ & 85 & 34.0 & 49 & & 19.6 \\
\hline Mean \pm sd & $2.1 \pm 2.3$ & & $2.3 \pm 2.4$ & & \\
\hline \multicolumn{6}{|l|}{ Parity } \\
\hline - Low risk (2-4 times) & 134 & 53.6 & 147 & & 58.8 \\
\hline - High risk ( 1 or $\geq 5$ times $)$ & 116 & 46.4 & 103 & & 41.2 \\
\hline Mean \pm sd & $2.9 \pm 1.7$ & & $2.4 \pm 1.4$ & & \\
\hline \multicolumn{6}{|l|}{ Education level } \\
\hline - Elementary school & 55 & 22.0 & 47 & & 18.8 \\
\hline - Junior high school & 80 & 32.0 & 68 & & 27.2 \\
\hline - Senior high school & 86 & 34.0 & 99 & & 39.6 \\
\hline - Diploma & 22 & 8.8 & 26 & & 10.4 \\
\hline - Degree & 7 & 2.8 & 10 & & 4.0 \\
\hline \multicolumn{6}{|l|}{ Exclusive breastfeeding } \\
\hline - Non Exclusive breastfeeding & 230 & 92.0 & 117 & & 46.8 \\
\hline & 20 & 20.0 & 113 & & 53.2 \\
\hline
\end{tabular}


Table.3 Simple logistic regression analysis: Association between exclusive breastfeeding and neonatal mortality of LBW

\begin{tabular}{lrrrr}
\hline \multicolumn{1}{c}{ Variables } & $\begin{array}{c}\text { Case (250) } \\
\mathbf{f}(\mathbf{\%})\end{array}$ & $\begin{array}{c}\text { Group } \\
\text { Control (250) } \\
\mathbf{f}(\mathbf{\%})\end{array}$ & $\begin{array}{c}\text { OR } \\
\mathbf{9 5} \% \mathbf{C I}\end{array}$ & P Value \\
\hline $\begin{array}{l}\text { Exclusive of breast feeding } \\
-\begin{array}{l}\text { Non-exclusive } \\
\text { breastfeeding }\end{array}\end{array}$ & $230(92.0)$ & $117(46.8)$ & 13.0 & $<0.001^{*}$ \\
-\begin{tabular}{l} 
Exclusive breastfeeding \\
\hline
\end{tabular} & $20(8.0)$ & $133(53.2)$ & $(7.77-21.9)$ & \\
\hline
\end{tabular}

Significant variable: $p<0.05$

This study found that exclusive breastfeeding has impact on neonatal mortality of the LBW. The neonates who did not receive exclusive breastfeeding had a 13 times greater risk of death than neonates who received exclusive breastfeeding during neonatal period. There were some previous studies in which their findings in line with the present study. A study conducted in Ethiopia conclude that exclusive breastfeeding is the strongest predictor of infant survival in this predominantly rural setting where hygienic standards are poor (Biks et al.2015).

The other study found that risk of mortality was higher in non breastfed infants compared to exclusively breastfed infants 0-5 months of age (Sankar et al.2015). A study in Ghana found the association between exclusive breastfeeding and neonatal mortality. The risk of mortality was higher in non breastfed infants compared to exclusively breastfed infants $0-5$ months of age (Edmond et al, 2006). A literature review on the relationship between breastfeeding practices in the first month of life and neonatal mortality found that breastfeeding helps prevent hypothermia and hypoglycemia in newborn babies, which are contributory causes of early neonatal deaths especially among low birth weight and premature babies.During the late neonatal period, most deaths in developing countries are due to infections such as sepsis, acute respiratory tract infection, meningitis, omphalitis and diarrhea. Colostrum and breastfeeding, especially exclusive breastfeeding protects against such deaths (Huffman et al., 2001).

WHO and UNICEF recommendations on breastfeeding are as follows: initiation of breastfeeding within the first hour after the birth; exclusive breastfeeding for the first six months; and continued breastfeeding for two years or more, together with safe, nutritionally adequate, age appropriate, responsive complementary feeding starting in the sixth month (UNICEF 2008).
Feeding unsupplemented mother's own milk in pre-term infants $<1500 \mathrm{~g}$ resulted in slower weight and length gains, but the implications of this slower growth are unclear and there is not enough evidence to assess if it increased the risk of malnutrition. Long-term beneficial effects of breastfeeding on blood pressure, serum lipid profile or pro-insulin levels have also been reported for pre-term infants. There are limited data on most outcomes in term LBW infants; the available data suggest that improved infection and neurodevelopmental outcomes associated with feeding mother's milk in preterm infants are also seen in this group (Edmond et al., 2007).

In a qualitative study about breast feeding practice in Aceh found some reasons why the mothers did not give breastfeeding as an exclusive feed. Those reasons were: less breast milk so that the family worried that the baby was not fed enough, a culture that assumed breast milk was a virus, and a culture that assumed only breast milk as a single feed was not enough for the baby. The reasons for giving breast milk as the single feed were: good knowledge and good habit. Interviews with midwives found that still many neonates including the LBW neonates did not receive exclusive breastfeeding (Satrinawati, 2014).

Breastfeeding has an extraordinary range of benefits. It has a profound impact on a child's survival, health, nutrition and development. Breast milk provides all of the nutrients, vitamins and minerals an infant needs for growth for the first six months, and no other liquids or food is needed. In addition, breast milk carries antibodies from the mother that help combat disease. The act of breastfeeding itself stimulates the proper growth of the mouth and jaw, and secretion of hormones for digestion and satiety. Breastfeeding creates a special bond between mother and baby and the interaction between the mother 
and child during breastfeeding has positive repercussions for life, in terms of stimulation, behavior, speech, sense of well being and security and how the child relates to other people. Breastfeeding also lowers the risk of chronic conditions later in life, such as obesity, high cholesterol, high blood pressure, diabetes, childhood asthma and childhood leukaemias. Studies have shown that breastfed infants do better on intelligence and behavior tests in adulthood than formula-fed babies (UNICEF 2008).

\section{References}

Biks, G.A., Berhane, Y., Worku, A \&Gete, Y.K. 2015. Exclusive breastfeeding is the strongest predictor of infant survival in Northwest Ethiopia: a Longitudinal study. Journal of health, population and nutrition. 34;9.

Cernadas, J.M.C., Carroli, G., Lardizábal,J.2006. Effect of timing of cord clamping on neonatal venous hematocrit values and clinical outcome at term: a randomized, controlled trial: In reply. Pediatrics journal, 118:13181319

Edmond, K.M., Zandoh, C., Quigley, M.A., Etego.S.A.,Agyei, S.O \&Kirkwood.B.R. 2006. Delayed Breastfeeding Initiation Increases Risk of Neontal Mortality. Pediatric journal. Vol 117/3

Edmond, K.M., Kirkwood, B. R., Etego, S.A., Agyei, S. O \& Hurt. L. S. 2007. Effect of Early Infant Feeding Practice on Infection - Specific Neonatal Mortality: an Investigation of the Causal Link Observational data From Rural Ghana. Am J Clin Nutr.2007;86:1126-31.

Huffman, S.L, Zehner, E. R \&Victora C.2001. Can Improvement in breast-feeding practice reduce neonatal mortality in developing countries? Midwifery.17 (2); 8092.

Lawn,J.,McCarthy,B.J., Ross.S.R. 2005. The Healthy Newborn: A Reference Manual for Program Managers. World Health Organization (WHO), Center for Disease Control \& Prevention (CDC), California Children Health Initiative (CCHI) and Care.USA.

Kemenkes RI: 2013. Balitbangkes. RisetKesehatanDasar 2013. Kemenkes RI. Jakarta

Kemenkes RI. 2017. Hasilpemantauan status gizi (PSG) tahun 2016. Direktorat GiziMasyaraka; Direktorat Jendral Kesehatan Masyarakat. Kemenkes RI.Jakarta

Riordan, J. 2004. The biological specificity of breast milk. In: Breastfeeding and human lactation. Jones and Bartlett, Boston, USA

How to cite this article:

Satrinawati Berkat. 2018. Exclusive Breastfeeding and the Impact on Neonatal Mortality of Low Birth Weight. Int.J.Curr.Res.Aca.Rev. 6(6), 9-15. doi: https://doi.org/10.20546/ijcrar.2018.606.002
Safri, M. 2018. Cow's milk consumption and the incident of wheezing in children. International journal of current research and academic review. Vol 6 Number 4

Safri, M., Addillah, M.D., Putra, AR., Kurnia, B and Muhsin.2018. Comparison of exclusive and non exclusive breast feeding with the incidence of Allergic Rhinitis in Children. International journal of current research and academic review.Vol 6 Number 4

Sankar, M.J., Sinha, B., Chowdhury, R., Bhandari, W., Taneja, S., Martines, J \&Bahl, R. 2015. Optimal breastfeeding practice and Infant and child mortality: A systematic review and meta analysis. ActaPaedictria: 104, PP: 3-13

Satrinawati.2014. Determinant factor of neonatal mortality among low birth weight neonate in Aceh province Indonesia. Ph.D Thesis. National University of Malaysia. Kuala Lumpur, Malaysia.

UNICEF.2008. The State of the World's Children 2009: Maternal and Newborn.New York. World Health Organization \& United Nations Children's Fund.

UNICEF.2014. Undernourishment in the womb can lead to diminished potential and predisposes infants to early death. Available at: http://data.unicef.org/nutrition/lowbirthweight.

UNICEF. 2018. Data: Monitoring the situation of children and women; neonatal mortality. Available at: https://data.unicef.org/topic/child-survival/neonatalmortality/

United Nation (UN). 2015. The global strategy for women's, children's and adolescents' health (2016- 2030). Available at: http://www.everywomaneverychild.org/

WHO. 2009. Infant \& young child feeding; model chapter for textbooks for medical student \& allied health professional. Geneva. Switzerland

World Health Organization.2016. Global health observatory (GHO) data; neonatal mortality. Available at http://www.who.int/gho/child_health/mortality/neonatal_t ext/en/

World Health Organization (WHO). 2017. 10 Fact of breastfeeding. Available at: http://www.who.int/features/factfiles/breastfeeding/en/

WHO. 2018. Nutrition; Breastfeeding. Available at: http://www.who.int/nutrition/topics/exclusive_breastfeedi ng/en/

WHO \& UNICEF.2004.Low birth Weight: Country, Regional, Global Estimates. New York. World Health Organization \& United Nations Children's Fund. 